\title{
DYNAMIC MECHANICAL THERMAL ANALYSIS (DMTA) OF THERMOPLASTIC NATURAL RUBBER (TPNR) BARIUM FERRITE $\left(\mathrm{BaFe}_{12} \mathrm{O}_{19}\right)$ COMPOSITES
}

\author{
S. Hamdan* \\ Faculty of Engineering, Universiti Malaysia Sarawak, Samarahan, \\ Sarawak, Malaysia \\ D.M.A. Hashim \\ Faculty of Science, Universiti Teknologi Mara, Samarahan Campus, \\ Sarawak, Malaysia
}

\section{Yusop}

Faculty of Science, Universiti Teknologi Malaysia, Skudai, Johor, Malaysia

Received 28 August 2003, Accepted 24 November 2003

\begin{abstract}
The dynamic mechanical thermal analysis (DMTA) of thermoplastic natural rubber (TPNR) filled with 0-6 volume percentage of barium ferrite was performed using a Polymer LaboratoryDynamic Mechanical Thermal Analyser (PL-DMTA) over a range of temperature from -100 to $100^{\circ} \mathrm{C}$ at $10 \mathrm{hz}$. The results showed that the storage modulus ( $\left.\mathrm{E}^{\prime}\right)$ of the composites below the transition temperature increase with filler content up to $\sim-4$ volume percentage. Incorporation of the filler does not change the matrix glass transition that occurs around $-40^{\circ} \mathrm{C}$ but the damping curve becomes broader with increasing filler content. The addition of filler in the composite does not affect the glass transition and melting temperature. The blend of TPNR and barium ferrite powder is only a physical mixture that does not act chemically.
\end{abstract}

Keywords: DMTA, TPNR, barium ferrite, storage modulus (E') and loss tangent (tan $\delta$ )

\section{INTRODUCTION}

Magnetic polymer composites have gained considerable research interest since 1955 due to the rapid development of the electronic instruments, household utensils, audio equipment and certain applications subjected to vibration or load ${ }^{1}$. The aim of this work is to produce an ideal composite

Corresponding author-email: hsinin@feng.unimas.my 
with optimum filler composition. Since the usage of filler can be seen as improving the mechanical and physical properties of composite it is expected that the ideal composite will yield maximum E' in the dynamic mechanical testing. Thus, it is felt important to look into the composites performances related to their dynamic mechanical thermal properties that can be studied via dynamic mechanical testing. This test measure the response of a material to a sinusoidal stress which yield valuable structural information of the filled and unfilled systems when they are subjected to dynamic load over a wide range of temperature and frequency ${ }^{2}$.

Compared to ceramic magnets, the polymer composites offer ease of processing and can be design into complex shapes. The advantage of thermoplastic natural rubber (TPNR) is its low preparation cost, the ability to process in thermoplastics machine without vulcanisation agent, the residue from the blend can be reuse and the product from the recycle process achieve similar tensile strength although had been recycle up to 10 times $^{3}$. Blend with higher NR content showed rubbery characteristics whilst higher polyolefin content produced semi rigid blend ${ }^{4}$. In this work it is assume that blending of 30\% NR and 70\% LLDPE with Liquid Natural Rubber (LNR) as compatibilizer produce an ideal blend with optimum dynamic mechanical thermal properties. This paper presents the results of dynamic mechanical thermal analysis, thermal analysis and $\mathrm{X}$ ray diffraction analysis of some of thermoplastic natural rubber (TPNR)-barium ferrite $\left(\mathrm{BaFe}_{12} \mathrm{O}_{19}\right)$ composites at various filler concentration.

\section{MATERIALS AND METHODS}

The natural rubber (NR) was obtained from Rubber Research Institute Malaysia (RRIM) and the Linear Low Density Poly Ethylene (LLDPE) was purchased from Dow Plastics. Blending of $30 \%$ NR and 70\% LLDPE with Liqiud Natural Rubber (LNR) as compatibilizer were carried out using an internal mixer machine, Brabender Plasticorder PL2000. The process was done at $135^{\circ} \mathrm{C}$ with rotor speed of 40 rotations per minute for 12 minutes. $\mathrm{BaFe}_{12} \mathrm{O}_{19}$ (obtained from Aldrich) was used as filler at various content from 0-6 vol. \% using the same processing conditions. The average particle size of the filler was about -350 mesh and the bulk density was $5.3 \mathrm{~g} / \mathrm{cm}^{3}$. Dynamic mechanical thermal analysis was performed using a Polymer LaboratoriesDynamic Mechanical Thermal Analyser (PL-DMTA) on a sample of approximately $30 \mathrm{~mm} \mathrm{x}$ $10 \mathrm{~mm}$ x $1 \mathrm{~mm}$ under dual-cantilever bending mode. Data were obtained at $10 \mathrm{hz}$, 4 strain from -100 to $100^{\circ} \mathrm{C}$ using heating rate of $2^{\circ} \mathrm{C} / \mathrm{min}$.

The thermal properties were studied using Mettler Toledo DSC $851^{\mathrm{e}}$ thermal analyser. The sample are cooled to $-110^{\circ} \mathrm{C}$ at $10^{\circ} \mathrm{C} / \mathrm{min}$ and reheated at the same rate up to $160^{\circ} \mathrm{C}$. The X-ray diffraction was performed on the samples using a Siemens D-5000 diffractometer with the following parameters: $\mathrm{CuK}_{\alpha}, 40 \mathrm{kV}$ and $0.04^{\circ}$ step-scan. The data collection angle $2 \theta$ was in the range of $15-75^{\circ}$. The microscopic morphology was taken using scanning electron microscope (SEM) model Philips XL-30. 


\section{RESULTS AND DISCUSSIONS}

\subsection{Dynamic mechanical thermal analysis}

The properties obtained from the dynamic mechanical thermal analysis are the storage modulus $\left(\mathrm{E}^{\prime}\right)$ and loss tangent $\left(\tan \delta\right.$ ) that is recorded as a function of temperature from -100 to $100^{\circ} \mathrm{C}$ and showed in figure 1 and 2 respectively. Figure 1a showed the inset of figure 1 for temperature between -60 to $-20^{\circ} \mathrm{C}$. All the specimens showed a glassy state that is followed by the rubbery state. In general, the storage modulus, $\mathrm{E}^{\prime}$ is found to increase with increasing barium ferrite content up to 4 vol. \% below the glass transition temperature. This indicates that incorporation of the ferrite filler has improved the stiffness of the composites and the dependence of $\mathrm{E}^{\prime}$ on

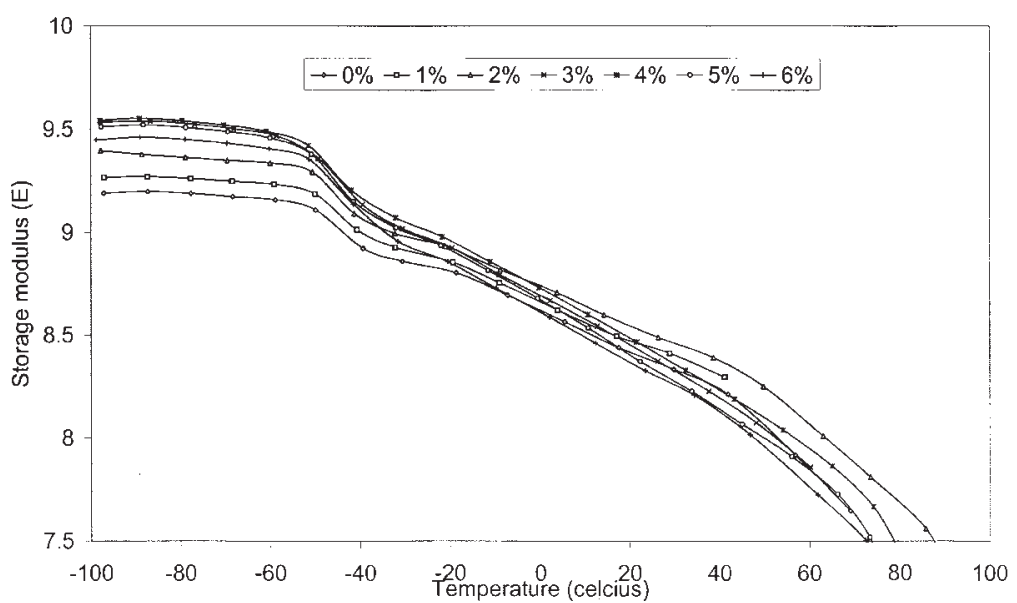

Figure 1 : Storage modulus versus temperature for TPNR and TPNR composites

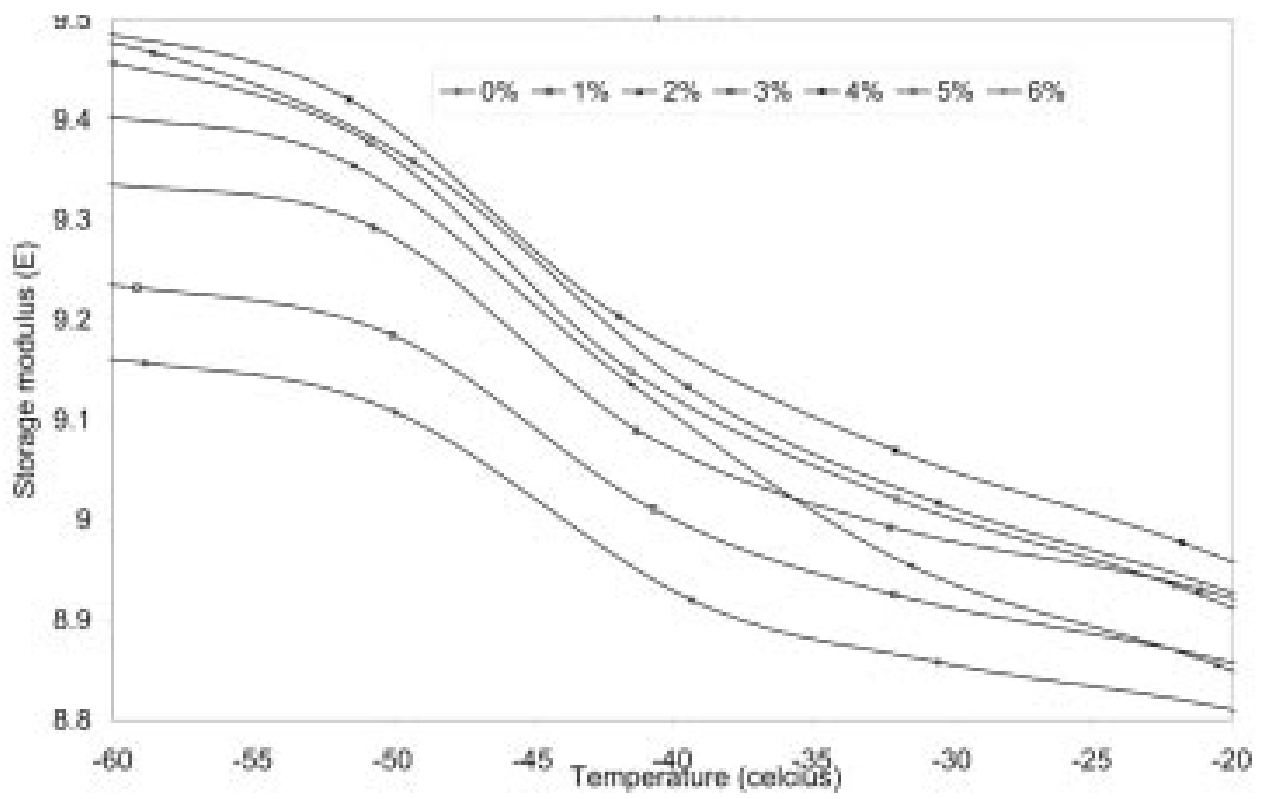

Figure 1a : Inset of storage modulus versus temperature for TPNR and TPNR compisites 
filler loading is more pronounced around the glassy region. The drop in the storage modulus with temperature during the transition from the glassy to the rubbery state occurs around $-40^{\circ}$ $\mathrm{C}$ for all specimens. The $\mathrm{E}^{\prime}$ increases with filler content up to 3-4 vol. \% and then reduced on further addition of the filler. The referee doubt why does the E' of the composite containing $6 \%$ filler was lower than that of which containing $4 \%$ and $5 \%$ filler, but the trend in figure 1 clearly showed the gradual decrease as the filler reached $4 \%$ i.e $6 \%<5 \%<4 \%$. The author does not have much explanation but only assumed a critical threshold value has been reached. It is assumed that the composite with 3-4 vol. \% of barium ferrite has reached a critical threshold value of filler content with respect to dynamic mechanical properties where the filler is no longer separated by the polymer matrices ${ }^{5,6}$.

The damping property ( $\tan \delta$ ), as the ratio of the dynamic loss modulus (or viscous) to the dynamic storage modulus (or elastic), is related to the molecular motions and phase transitions. Tan $\delta$ is therefore sensitive to all molecular movement occurring in polymers. For composites, the molecular movement at the interface contribute to the value of $\tan \delta$ that enables us to determine the bonding between the interface of the matrix and the fibre. Figure 2 displays the results obtained for $\tan \delta$. Since ferrite powder is rigid filler it dissipates energy and thus the height of damping peak increases with filler content (except 2 vol. \%). It is admitted that there is a non-linear relationship between $\tan \delta$ peak height and $\%$ of filler (most surprising is the 2 vol. \%). In this case the author wish to only assume the interpretation to avoid misleading interpretation. (The author is grateful if the editor/referee can add on this). It is assume that the present of filler content has increases the damping probably by particle-particle friction where particles hold one another as in weak agglomerates or particle-polymer friction where there is no adhesion at the interface ${ }^{7}$.

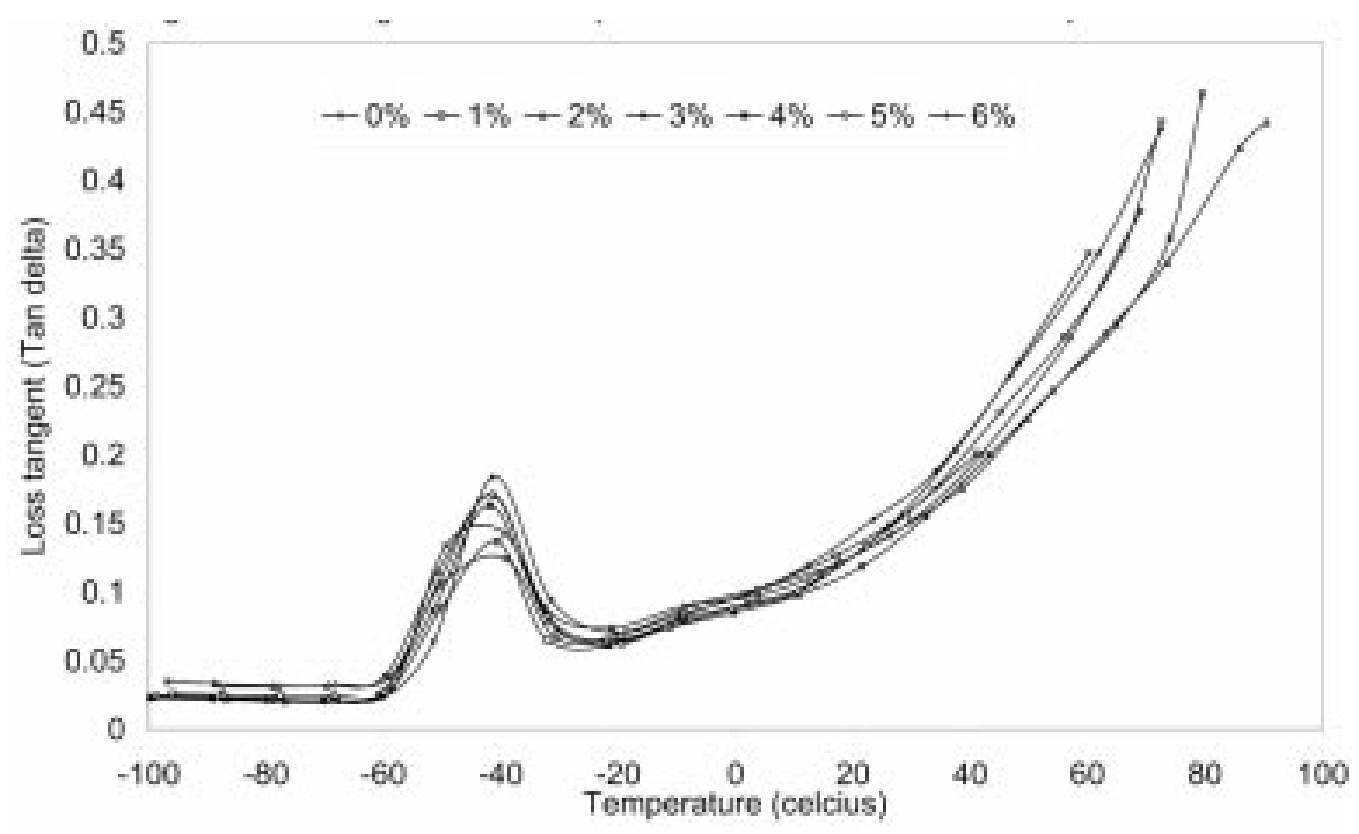

Figure 2: Loss tangent versus temperature for TPNR and TPNR composites 


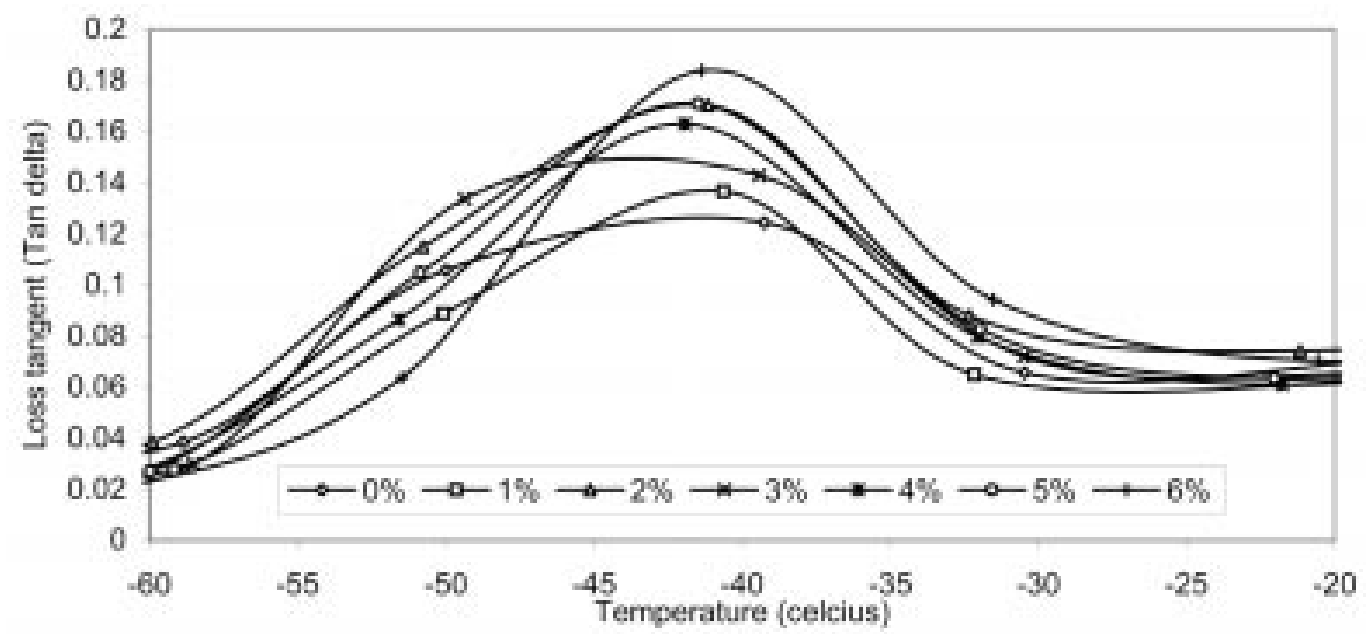

Figure 2a : Inset of loss tangent versus temperature for TPNR and TPNR composites

The $\tan \delta$ peaks observed correspond to the glass transition temperature $\left(\mathrm{T}_{\mathrm{g}}\right)$ of the matrix. The $\mathrm{T}_{\mathrm{g}}$ around $-40^{\circ} \mathrm{C}$ does not change with filler loading. This indicates poor interaction between filler and matrix. Figure $2 \mathrm{a}$ showed the inset of figure 2 for temperature between -60 to $-20^{\circ} \mathrm{C}$. The damping peak becomes broader with increasing filler content. This behaviour suggests that the filler introduces many kinds of relaxation modes of TPNR chains ${ }^{8}$.

\subsection{Thermal analysis}

The DSC thermograms for TPNR and TPNR composites are displayed in figure 3. In figure 3, TPNR displayed both the amorphous and crystalline character as showed by the glass transition temperature $\mathrm{T}_{\mathrm{g}}$ (due to $\mathrm{NR}$ at $\sim-60^{\circ} \mathrm{C}$ ) and the melting temperature $\mathrm{T}_{\mathrm{m}}$ (due to LLDPE at $\sim 110^{\circ} \mathrm{C}$ and $\sim 120^{\circ} \mathrm{C}$ ) respectively. (The existence of a single $\mathrm{T}_{\mathrm{g}}$ value confirmed the highly homogenous distribution of filler in TPNR-The author agree to omit this statement). The slight changes in the $\mathrm{T}_{\mathrm{g}}$ value may be due to the effect of filler in TPNR that explained the degree of orientation between them. A step transition at $50^{\circ} \mathrm{C}$ is also noticeable. If a polymer blend components are incompatible, each component exhibit its own un-pertubed relaxation process 9 . The step transitions at $50^{\circ} \mathrm{C}$ are probably associated with pre-melting ${ }^{10}$. It is the result of motion or deformations within the interfacial regions (tie molecules, folds, loops, etc) that are activated as a consequence of chain mobility in the crystal ${ }^{11}$.

There are 2 melting peaks. The small peak at $\sim 110^{\circ} \mathrm{C}$ is due to the melting of LLDPE whereas the main peak at $\sim 120^{\circ} \mathrm{C}$ is due to the melting of linear crystal in LLDPE. Only one peak is observed if polyethylene contained 0 or $100 \%$ linear chain ${ }^{12}$. This finding showed that the LLDPE do not contain $100 \%$ linear chains. The addition of filler in the composite does not affect the glass transition and melting temperature. This obviously indicates that the filler does not disturb the structure of TPNR and only physical mixture between TPNR and barium ferrite powder occur. This finding is consistent with the structural analysis using XRD. 


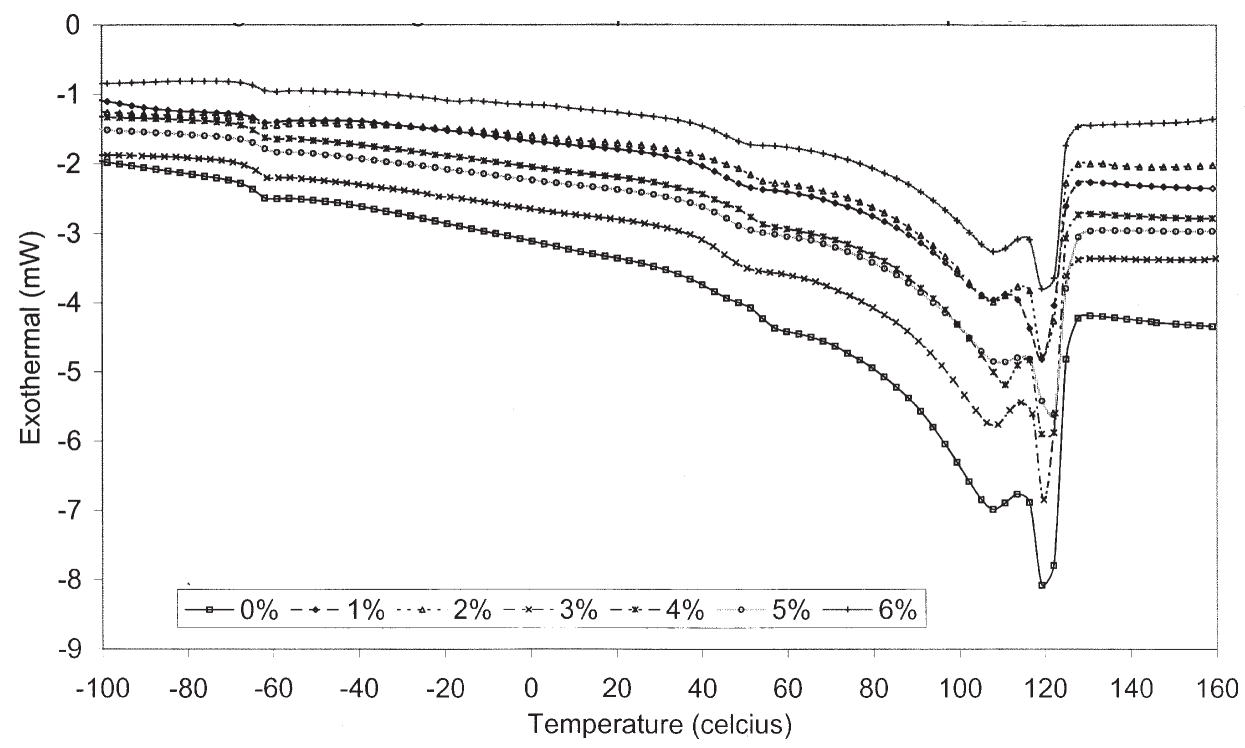

Figure 3 : Thermogram of DSC for pure TPNR and TPNR composites

\subsection{X-Ray diffraction analysis}

The $\mathrm{X}$ ray diffraction analysis of TPNR, TPNR composites and barium ferrite is showed in figure 4. Pure TPNR showed 2 peaks at $22^{\circ}$ and $24^{\circ}$ with $\mathrm{d}$ values of $4.0858 \mathrm{~A}$ and $3.6901 \mathrm{~A}$



Figure 4: X-ray diffraction for pure TPNR, TPNR composites and barium ferrite 
respectively. These peaks are due to the polymeric LLDPE that have the semi-crystalline character. With TPNR composites the $X$ ray diffraction changes with the existence of new peak at $30^{\circ}$. These new peaks are due to barium ferrite that is highly crystalline. The significant increased of these new peaks with the increment of filler addition at the same time reduce the TPNR semicrystalline peaks at $22^{\circ}$ and $24^{\circ}$. This figure confirmed that the crystallinity of the composites is due to the filler and increase accordingly with the filler content. The non-existence of new peak except those from TPNR and barium ferrite showed that the blend of TPNR and barium ferrite powder is only a physical mixture that does not act chemically.

\subsection{Scanning electron microscopy (SEM)}

The distribution of barium ferrite in pure TPNR and TPNR composite with 2, 4 and 6 vol. \% of filler at 1000x magnification is showed in figure 5a-5d respectively. Figure 5a showed the morphology of the surfaces of pure TPNR with numerous amount of pores (as small black spot) that is well distributed at the sample surfaces. From figure 5b-5d the SEM micrographs reveals that the filler is identified as small white spot that is evenly distributed. These small white spot increased and became significant with the addition of filler. The fractured surfaces (at 1000x magnification) failed due to elongation in the tensile test for 4 and 6 vol. \% composites are shown in figure $5 \mathrm{e}$ and $5 \mathrm{f}$ respectively. The fractured sample yield fibrils that showed the interaction and dislocation between the filler and matrices.

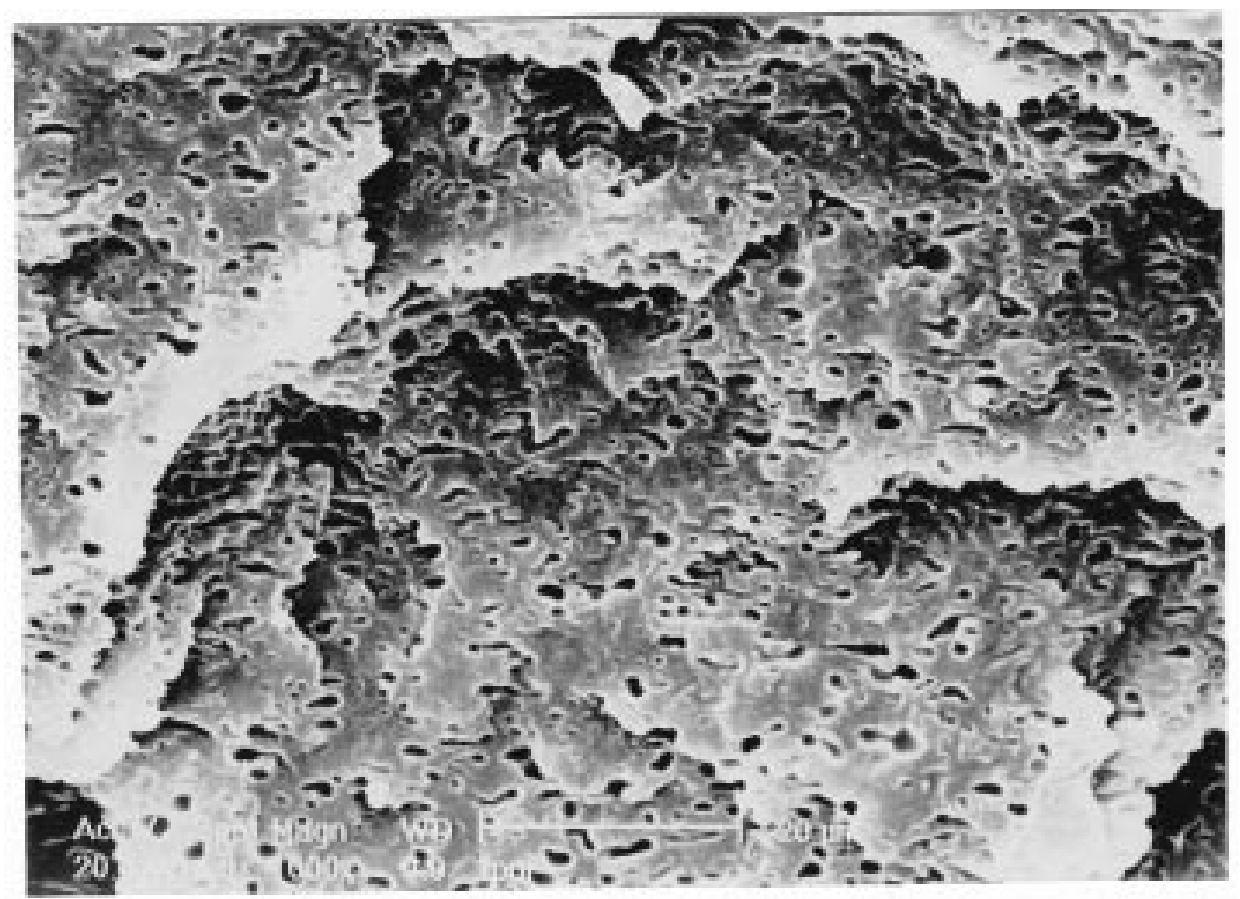

Figure 5a: SEM micrograph for pure TPNR 




Figure 5b : SEM micrograph for 2 vol.\% TPNR composite



Figure 5c: SEM micrograph for 4 vol.\% TPNR composite 


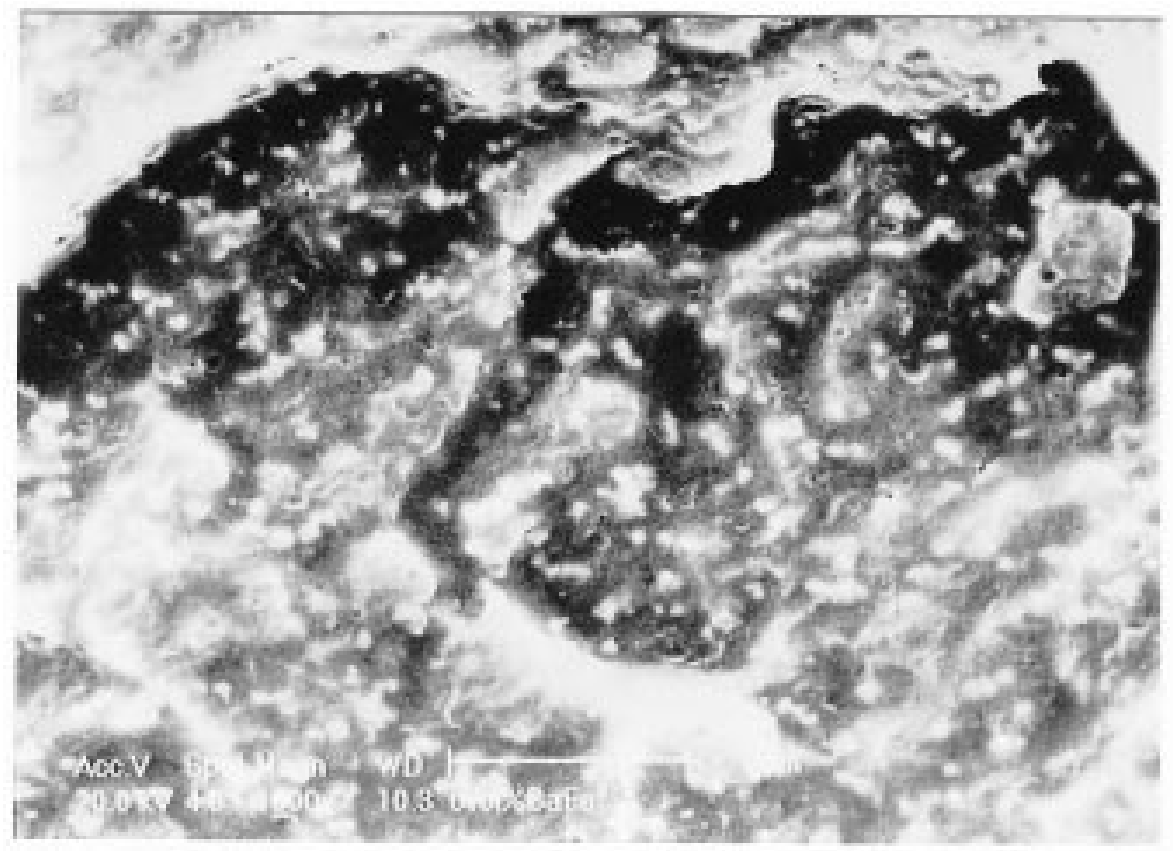

Figure 5d : SEM micrograph for 6 vol.\% TPNR composite

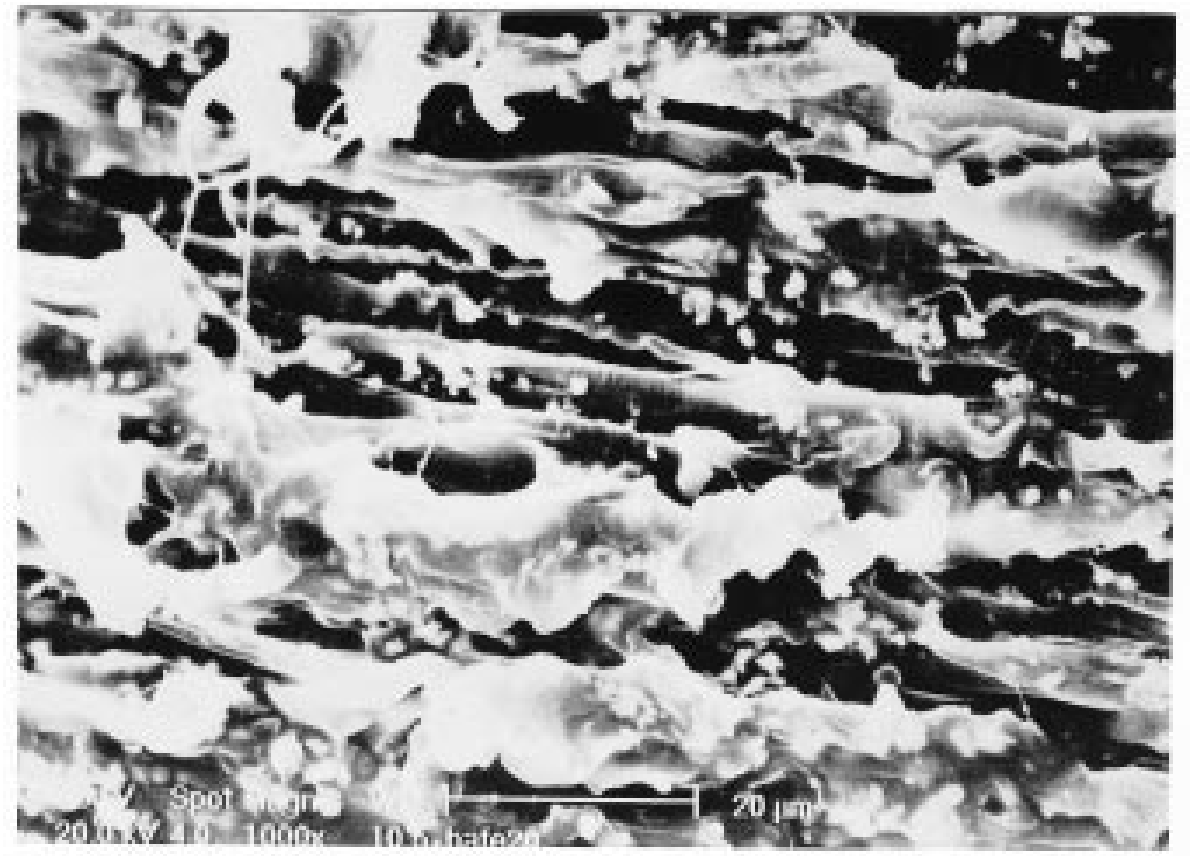

Figure 5e : SEM micrograph for fractured 4 vol.\% TPNR composite 


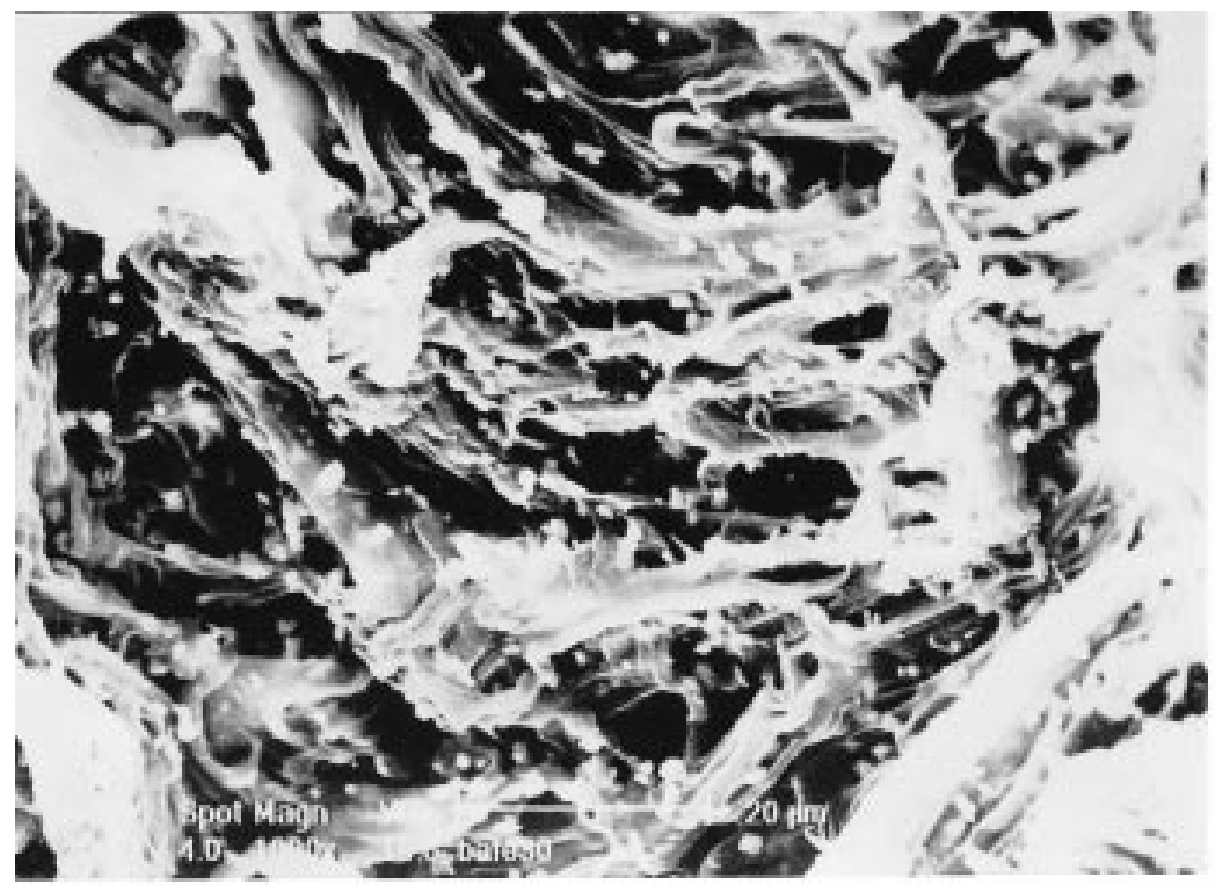

Figure 5f : SEM micrograph for fractured 6 vol.\% TPNR composite

\section{CONCLUSION}

Incorporation of the barium ferrite filler into the TPNR (30NR/70LLDPE) matrix has increased the storage modulus of the composites. Beyond 3-4 vol. \% filler loading, barium ferrite causes a decrease in the storage modulus of the composites. The filler does not affect the glass transition temperature $\left(\mathrm{T}_{\mathrm{g}}\right)$ of TPNR matrices that indicate the blend of TPNR and barium ferrite powder is only a physical mixture that does not act chemically. The non-existence of new peak in the blend from X-ray diffraction confirmed that TPNR and barium ferrite does not act chemically.

\section{REFERENCES}

1. Gokturk, H.S. and Fiske, G. (1991), IEEE Trans. Mag., vol. 29, no. 6, pp. 4170-4176.

2. Saini, D.R., Shenoy, A.V and Nadkarni, N.M. (1984), J. Appl. Polym, vol. 29, pp. 41234143.

3. Che Som, S. (1994), MSc theses, Universiti Kebangsaan Malaysia (in Malaysian language).

4. Elliot, D.J. and Thinker, A.J. (1988), Natural rubber science and technology, Oxford: Oxford University Press, pp. 328-335.

5. Sombatsompop, N. (1999), J. Appl. Polym. Sci., vol. 74, pp. 1129-1139.

6. Yu, S. and Hing, P. (2000), J. Appl. Polym. Sci., vol. 78, pp. 1348-1353.

7. Nielsen, L. E. and Landel, R.F. (1994), Mechanical Properties of Polymers and Composites. New York: Marcel Dekker, Inc. 
8. Ogata, N., Kawakage, S. and Ogihara, T. (1997), Polymer., vol. 38, no. 20, pp. 51155118.

9. Wetton, R.E. and Corish, P.J. (1989), Polymer Testing, vol. 8, pp. 303-312

10. Raff, R.A.V. (1967) in Encyclopedia of Polymer Science and Technology, vol. 6, H.F. Mark et.al. eds., Wiley, New York, pp. 275-332.

11. Yash, P.K., Edith A.T., Thomas, J.T., Virgil, V.V. and Richard F.A. (1985), Macromolecules, vol. 18, pp. 1302-1309.

12. Hatakeyama, T. and Quinn, F.X. (1994), Thermal Analysis: Fundamentals and applications to polymer science, Chichester, John Wiley \& Sons, Ltd. 